\title{
S⿵冂- \\ La práctica de investigación en el campo disciplinar de Trabajo Social
}

\author{
CARMEN InÉS LeRA \\ LICENCIADA EN TRABAJO SOCIAL \\ UNIVERSIDAD NACIONAL DE ENTRE RÍOS (ARGENTINA)
}

Resumen: El presente trabajo reflexiona sobre la situación de la investigación en el campo del Trabajo Social en Argentina y más específicamente su desarrollo en la Facultad de Trabajo Social de la Universidad Nacional de Entre Ríos. El recorrido se inicia recuperando a los precursores en el ámbito de las investigaciones sociales que básicamente están ligadas a los movimientos de reforma social. En esa breve incursión resultan interesantes los aportes provenientes de la historiografía de las mujeres. Luego se aborda la actualidad de la investigación de Trabajo Social en el contexto argentino donde se avizoran renovados desarrollos que contribuyen a la consolidación del campo profesional.

Palabras clave: investigación social, precursores, trabajo social, investigación en trabajo social en Argentina. 


\title{
Research practice in the field of social work. Some notes... to encourage further research
}

\begin{abstract}
This paper serves to reflect on the research situation in the field of social work in Argentina and more specifically its development at the Faculty of Social Work in the National University of Entre Ríos. We started off by recovering the forerunners of social research, which is mainly linked to social reform movements. In this brief incursion into the field, the contributions based on the historiography of women proved to be of interest. The research into social work was then looked at in its current state within the Argentinean context, where renewed progress was examined leading to the consolidation of the professional field.
\end{abstract}

Keywords: social research, forerunners, social work, research into social work in Argentina. 


\section{La práctica de investigación en el campo disciplinar de Trabajo Social}

Carmen Inés Lera

\section{Introducción}

El presente artículo se propone compartir y abrir "nuevas" interlocuciones, a propósito de un "viejo" tema que en esta parte del planeta viene teniendo cierta centralidad. El mismo está referido a la relación de Trabajo Social con la producción de conocimientos. Relación que si bien en este caso remite a los modos en que la disciplina ha ido incorporando a su patrimonio las acumulaciones provenientes de prácticas investigativas, también nos habla de la vinculación con el conocimiento teórico y con la ciencia social en general.

Es bueno aclarar que estas reflexiones deben ser entendidas en el contexto del estado de debate que se viene dando en la Facultad de Trabajo Social de la Universidad Nacional de Entre Ríos (Argentina), preocupaciones que por otra parte son compartidas con profesionales de otras instituciones académicas.

Como mencionáramos en el párrafo anterior el tema de la producción de conocimientos en Trabajo Social aparece con cierta energía en la agenda actual de discusiones. Su enunciación aparece con mayor vitalidad a nivel de las unidades de formación y es aún débil en el resto del campo profesional; esto último ameritaría un mayor análisis por las implicancias que ello trae aparejado para la consolidación de la disciplina pero su abordaje excede los términos del presente trabajo.

Retomando cabe preguntarnos ¿por qué estamos problematizando sobre esa cuestión?, y si ésta ¿es nueva para la disciplina?

En la idea de ir bosquejando posibles respuestas, se inten- 
tará construir, a modo de una genealogía, la presencia de la categoría investigación en el campo del Trabajo Social, pretendiendo relevar los debates, desafíos, ausencias en torno a este aspecto.

Ya en tarea, encontramos que estas inquietudes nos acompañan prácticamente desde los orígenes de nuestra profesión y son parte renovada de las preocupaciones actuales. No se trata de un desvelo lineal y permanente sino que presenta continuidades y rupturas que resultan importante resignificar.

\section{En la búsqueda de viejos debates}

Pretendiendo seguir la huella acerca de esta inquietud podemos ver que nuestra profesión se institucionaliza intentando justamente diferenciarse, distinguirse de las prácticas de acción social llevadas a cabo desde la caridad y la beneficencia.

Del conocimiento intuitivo de los males sociales, característico de la estrategia de la beneficencia, se llega a plantear la necesidad de contar con un exacto conocimiento del estado de necesidad mediante la realización de los correspondientes diagnósticos sociales. Mientras que la vieja asistencia procura ayudar a un estado de necesidad no comprobado, ataca las consecuencias de los males y es llevada a cabo por amateurs o personas de buena voluntad, la asistencia moderna se autodefine como ayuda a un estado de necesidad comprobado y va a las raíces del mismo, su etiología, es por eso que "busca, investiga, diagnostica, ficha. Fanfani (1989).

Este proceso fue dando lugar a la consolidación de personal especializado y en él se inscriben los asistentes sociales.

Este espíritu de la época, signado por una cada vez mayor relevancia de la racionalidad científica impregnó la intervención social. El conocimiento científico era la herramienta que permitiría "distinguir" a los amateurs de los especialistas. La apuesta en este período fundacional de la profesión no estaba centrada en la producción de conocimiento sino en el uso de conocimientos científicos.

Distintos autores señalan que la investigación social (no investigación en servicio social pero con posteriores puntos de encuentro) está muy ligada a la filantropía, lo que nos lleva a hacer otros rodeos acerca de nuestras tradiciones. 


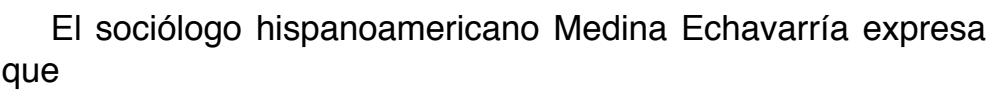

... aparece fuera de toda duda la influencia de la filantropía en el origen y desarrollo de la investigación social. Las dos formas más características de ésta, Social Survey y Case study, tienen conexión evidente con impulsos y movimientos de beneficencia y reforma social. Vigetti (1965).

En coincidencia con este análisis, pero incorporando otra mirada, la de un escenario que se abría para las mujeres, Michelle Perrot, detalla las implicancias que la práctica de filantropía ofreció a las mujeres.

La autora ubica sus notas en el recorrer del siglo XIX planteando que la caridad, antiguo deber de las cristianas, hacía tiempo había sacado a las mujeres de sus casas: las visitas a pobres, enfermos, presos permitieron desplegar itinerarios por las ciudades antes vedados.

En la oscuridad de una beneficencia anónima quedó sepultada una inmensa energía cuyos efectos sociales son difíciles de medir. Sin embargo, para las mujeres la filantropía constituyó una experiencia nada despreciable, que modificó su percepción del mundo, su idea de sí mismas y, hasta cierto punto, su inserción pública. Perrot (2000).

Perrot continúa planteando que la visita a domicilio, destinada a la localización de los pobres merecedores se torna cada vez más rigurosa dando lugar a la encuesta, biográfica y familiar, lo que va dando lugar a verdaderos archivos de la pobreza. De esta manera las mujeres adquieren un saber social y una familiaridad con herramientas que luego van formando parte de los insumos profesionales entre los que se cuenta la asistencia social.

...la influencia de la filantropía tuvo efectos múltiples. A las mujeres burguesas les permitió descubrir otro mundo, y para algunas de ellas fue un verdadero choque. Se iniciaron en la gestión administrativa y financiera, en la comunicación y, sobre todo, en la investigación. Flora Tristán (Paseo de Londres, 1840), Betina Brentano (El libro de los pobres) fueron las primeras reporteras de la miseria... De esta manera, las mujeres acumularon saberes y prácticas que les confirieron una función potencial de expertas. A través del modesto personal retribuido de la London Mission o los settlements, 
a través de los informadores de uno y otro sexo instituidos por la ley francesa en los tribunales para la infancia (1912) y de las primeras mujeres inspectoras de mujeres (prisiones, escuelas, talleres y fábricas) acceden a funciones de autoridad y al trabajo social en vías de profesionalización". Perrot (2000).

La iniciación en estas prácticas les reporta a las mujeres herramientas de investigación y de gestión en la ayuda a los pobres. Si bien tratan de cambiar "hábitos y restaurar a las familias descalabradas", esta tarea moralizadora no excluye la compasión e incluso la rebelión contra la condición en que se encuentran las mujeres. Una serie de protestas se desencadenan en relación a la situación que viven por ejemplo las prostitutas y las trabajadoras textiles a domicilio.

La colección "Historia de las Mujeres" de las cuales Michelle Perrot es una de sus directoras, es solo un ejemplo de una línea historiográfica que se propone "sacar a las mujeres de la sombra de la historia". Esta perspectiva ofrece múltiples y fértiles aristas para la comprensión de los procesos de profesionalización de trabajo social y su problematización en torno a la configuración identitaria. Su lectura provoca la necesidad de alejarnos de análisis simplistas a la hora de mirarnos a nosotros mismos complejizando saludablemente nuestro pasado.

La historia más difundida muestra una "ausencia" de protagonistas mujeres, por ello la autora se obstina en rescatarlas. Esta omisión puede entenderse porque

... a medida que el pauperismo se convierte en "cuestión social", la intervención masculina se hace más imperiosa. ... Ya De Gérando (Le Visiteur du Pauvre, 1820) deseaba en el rango de los visitantes más bien hombres comprometidos en la vida activa y susceptibles de procurar trabajo. A finales del siglo, las grandes figuras de la filantropía son masculinas: Barrett, Booth, fundador del Ejército de Salvación; Henri Dunand, fundador de la Cruz Roja; Max Lazard, organizador de la primera conferencia internacional del desempleo (1910), etc. Perrot (2000).

\section{Cuando lo social no había sufrido las disputas disciplinares}

Al analizar el material de Trabajo Social que aborda la cuestión de la investigación podemos observar que los primeros 
debates en torno a esta práctica intentan distinguir las particularidades de la "investigación social" de la "investigación en servicio social".

Aquí resulta interesarte detenernos dado que los "precursores en investigación" citados por Trabajo Social coinciden con los mencionados por distintas disciplinas del campo de las ciencias sociales.

Valen como ejemplo: en Inglaterra John Howard (1726-1790) quien investigó sobre las condiciones de los detenidos, las cárceles y los carceleros. "Howard sobresale como figura señera de la reforma social. Recogió la evidencia para la acción mediante investigaciones sistemáticas" Macdonal (1966: 28); Sir Frederic Morton Eden (1766 - 1809) realizó estudios sobre la situación de los pobres; Charles Booth (1840-1916) se interesó en conocer y obtener una imagen verdadera de las condiciones de vida de la gente. Su obra conocida como Vida y trabajo de la población en Londres constituye una fuente permanente de consulta por sus aportes metodológicos (estadístico y cualitativo), rigurosidad, ingenio en la selección de técnicas de recolección de información, etc.

Entre los miembros del equipo que Booth conformó para llevar a cabo la investigación se encontraba Beatriz Webb (18581943) quien luego también se destacaría.

Por el lado de E.E. U.U. se rescata a Dorotea Lynde Dix (1802-1887) ligada a la reforma social americana, quien estudió las condiciones de vida de los enfermos; Edith Abbott se dedicó al estudio del trabajo infantil, delincuencia juvenil, inmigrantes, etc. Esta última fue una de las que contribuyó a la creación de la Chicago School of Civics and Philanthopy posteriormente -1920 - parte de la Universidad de Chicago, ahora Escuela de Administración del Servicio Social).

Hacia los primeros años del siglo XX, desde la Russell Sage Foundation, Mary Richmond (1861-1928) se esfuerza por sistematizar los conocimientos empleados en los procesos iniciales del estudio familiar e individual. Su obra Social diagnosis constituye un hito fundamental en la historia del Trabajo Social.

Otra línea, que se diferencia de la anterior, comienza a instalarse posteriormente: las casas de vecindades (Settlement house). Éstas reflejaban una nueva respuesta organizativa a la problemática de la industrialización y de la inmigración, introdu- 
ciendo un modelo alternativo de agencia para el servicio social, una especie de misión urbana. La primera casa settlement en EEUU, denominada Gremio del Vecindario, se estableció en la ciudad de Nueva York en 1886. Tres años después, Jane Adams y Ellen Gates Starr fundaron la Casa Hull en Chicago, que pasó a ser la más famosa de estos settements.

Y lo más importante de destacar es que a diferencia de los COS, de corriente individualista, los settlements se enfocaban en las causas ambientales de la pobreza y en extender las oportunidades de trabajo a los pobres. Realizaron investigaciones, ayudaron a sistematizar la justicia juvenil, establecieron un programa de pensiones para viudas, iniciaron legislación para prohibir el empleo de menores, e introdujeron reformas de salud pública bajo el concepto del seguro social. Otra problemática que ocupó un lugar de centralidad es la referida a la inmigración. Desde los settlements abogaron por mejorar las condiciones de los habitantes inmigrantes que vivían en los conventillos de esta zona de Chicago.

Investigaciones actuales refieren a los estrechos vínculos entre los sociólogos del Departamento de Sociología (conocida Escuela de Chicago) con Jane Addams y las trabajadoras sociales de Hull House que eran quienes en realidad hacían el trabajo de campo.

El listado podría continuar, pero nos interesa compartir algunas reflexiones. Por un lado, podemos visualizar que las motivaciones que dieron lugar a la necesidad de investigar estaban ligadas a situaciones de pobreza, discriminación, sufrimiento.

Por otro lado, las conclusiones a las que llegaban no solo tenían como objetivo el "conocer" sino que desde la denuncia buscaban ayuda temporal o permanente para los males que habían reportado. Una de las vías utilizada era la legislativa.

Muchos de los informes de investigación fueron presentados ante el Congreso, autoridades, políticos con el fin de provocar por parte de los funcionarios algún tipo de respuesta. La mayoría de estos investigadores, como menciona Medina Echavarría, eran referentes del movimiento de reforma social.

La vehemencia puesta de manifiesto en el desarrollo de las investigaciones por parte de estos precursores deja entrever que el sentido de las mismas iba en dirección a provocar alguna modificación a la situación estudiada. 
Asimismo de esta breve recuperación podemos observar que lo social como objeto científico todavía no había sufrido los "recortes disciplinares" y es así como estos pioneros de la investigación social son compartidos como precursores por la sociología, la antropología, la economía, etc.

Valen como ejemplo:

Se trata de Beatrice Potter, de soltera, más conocida después y en nuestros días por Beatrice Webb, apellido que adquiere al casarse con Sidney Webb, en julio de 1892, con quien firmará, desde entonces una larga cantidad de obras sociológicas e históricas enormemente influyentes, y que constituyen un corpus fundamental en nuestras disciplinas, historia y sociología... Castillo (2003).

Coincidiendo con este punto de vista, Ramos Gorostiza plantea que

...la obra de Beatrice Potter Webb (1858 - 1943) es difícilmente clasificable desde los cánones actuales de estrecha especialización, pues abarcó la historia económica, la metodología de las ciencias sociales, el análisis de las instituciones políticas, el estudio crítico de las teorías económicas, la reforma legal práctica, y la investigación sociológica aplicada. Ramos Gorostiza (2003).

\section{Las clasificaciones positivistas respecto a las ciencias}

\section{El lugar de Trabajo Social}

La institucionalización de las ciencias sociales (mediados del siglo XIX) desde la hegemonía positivista y al interior del incipiente sistema capitalista no solo parceló la realidad para que cada disciplina tomara una parte: sociología, economía, derecho, sino que consolidó otra nueva fragmentación entre el hacer y el pensar dando lugar a las disciplinas y las tecnologías.

En realidad, investigación social, sistematización de los impulsos filantrópicos, servicio social e investigación en servicio social, tienen puntos de contacto que indudablemente fueron más evidentes, llegando a confundirse, en el período de surgimiento. Vigetti (1965).

Esta cita pertenece a un texto Investigación en Servicio Social, de Ángela Teresa Vigetti, quien fuera directora de la 
Escuela de Servicio Social de Santa Fe (Argentina). Fue publicado hacia la década del 60 dando cuenta de su convicción por alentar la incorporación de la lógica investigativa en la formación y el trabajo profesional.

Angela Vigetti, en el tema investigación en servicio social fue considerada un referente nacional y latinoamericano. Por la agudeza de sus observaciones y por la proyección de su perspectiva es que podemos, a 40 años de sus escritos, tomar sus aportes en un fructífero diálogo con las discusiones actuales.

Vigetti se pregunta si hay diferencias entre la investigación social y la investigación en servicio social. Esta pregunta es compartida por otros en su época.

El texto Metodología de la investigación en Trabajo Social, compilado por Norman Polansky (Estados Unidos) da cuenta de esta inquietud. Estos distintos autores definen que el criterio de diferenciación se encuentra no tanto en el tema o en el método, sino en la función.

La función de la investigación del trabajo social es contribuir al desarrollo de un cuerpo sólido de conocimientos que sirva las metas y medios del trabajo social en todas sus ramificaciones. Macdonal (1966).

La autora Mary Macdonal, agrega más adelante:

Los objetivos del trabajador social y del investigador social son los mismos: sencillamente, la mejora de la práctica. Sin embargo caminan hacia objetivos por caminos muy distintos. El que ejerce esta profesión busca mezclar el conocimiento y la facultad para servir mejor a su cliente, sea individuo, grupo o comunidad. El investigador trata de ampliar y refinar el conocimiento de que dispone aquél. Macdonal (1966).

Si bien estos autores explicitan puntos de encuentro entre los dos tipos de investigaciones, sus posiciones se inclinan a ubicar a la investigación en trabajo social como investigación aplicada. Consideran que la misma se inicia o comienza a partir de problemas prácticos y los conocimientos producidos deben servir para la planificación o realización de programas de trabajo social. Por su parte, la investigación básica (fundamental o pura) tiene por objeto la acumulación de conocimientos para comprender el mundo prescindiendo de las consecuencias prácticas. 
Teresa Vigetti, en su texto incorpora además otras voces sobre estas distinciones con planteos básicamente similares.

La Dra. Erna Sailes, al resumir el informe de la Conferencia Regional Europea celebrada en 1959, dice: "Es necesario distinguir entre investigación social, en la cual el Asistente Social puede cooperar como miembro, y la investigación sobre cuestiones de servicio social, que el Asistente Social debe estar preparado para realizar porque él es el único que conoce los problemas. Vigetti (1965).

Estas inquietudes, presentes en los inicios del proceso de profesionalización, no tuvieron la expansión y la fuerza suficiente como para constituirse en una tendencia significativa que provocara, a la incipiente profesión, a incorporar la práctica investigativa como un requisito fundamental en la constitución de un campo profesional relativamente autónomo.

Desde la experiencia norteamericana en la Revista "Selecciones del Social Work" No 1 (marzo 1968) Harriet Bartlett en su artículo El lugar y la aplicación del saber expresa lo siguiente:

Una profesión se juzga también por el rigor de su pensamiento. Durante muchas décadas el servicio social ha tardado en asumir su responsabilidad en cuanto a la investigación. Cuando finalmente personas experimentadas en trabajos de investigación se reunieron con otros miembros de la profesión en una organización mancomunada, el movimiento progresó rápidamente... El volumen de los estudios actuales también va en aumento. Sin embargo, un examen de los inventarios anuales de investigación y listas de tesis doctorales, revela que las mismas se refieren en su mayor parte a servicios de instituciones y programas comunitarios. Sólo una pequeña parte trata de la práctica profesional, y un número aún más pequeño, del trabajador social en acción. A pesar de que la investigación formal se ha enseñado en las escuelas durante decenios, los trabajadores sociales en su mayoría no han adquirido la capacidad de pensamiento riguroso que es esencial para una profesión en vías de maduración. Bartlett (1968).

La Revista Mexicana de Sociología publica en 1959 un artículo denominado "Una Teoría de las Relaciones Entre la Ciencia Social y el Trabajo Social" de Ernest Greenwood. Dicho artículo es una versión revisada de un trabajo anterior datado en 1953. 
El artículo se inicia distinguiendo tres aspectos: a) características de las ciencias, incluyendo las ciencias sociales; b) características de las prácticas, con inclusión del trabajo social; c) relación entre trabajo social y ciencias sociales.

Al interior del primer punto, características de las ciencias, incluyendo las ciencias sociales, desarrolla la idea de ciencia y de ciencia social. Luego se detiene en la investigación como proceso que permite el crecimiento de la ciencia. Reconoce así dos tipos de investigación, pura y aplicada, que dan lugar respectivamente a la ciencia pura y ciencia aplicada pero ambas contribuyen a un solo y mismo cuerpo de conocimientos. Afirma que la finalidad es siempre probar y extender la teoría científica. "Una disciplina científica social es una totalidad unitaria, y ambos tipos de investigación no hacen sino alimentarla" Greenwood (1959).

Desde ese marco es que plantea que suele creerse que los trabajadores sociales realizan investigación aplicada, sin embargo ello no es así dado que no devienen de una ciencia básica propia. De allí que en el segundo aspecto abordado: $b$ ) características de las prácticas, con inclusión del trabajo social, profundiza en la ubicación del trabajo social como tecnología.

Convencionalmente, se establece una distinción tajante en términos de los materiales con los que se trabaja entre dos especies de este género, o sean, la ingeniería y la práctica. Los tecnólogos que tratan con materiales no humanos reciben el nombre de "ingenieros"; quienes tratan con seres humanos son denominados "prácticos"... Greenwood (1959).

Para el autor, los ejes del Trabajo Social son la acción y el cambio así como el control y para ello se vale del diagnóstico y tratamiento. Sostiene que es incorrecto llamar científico al práctico porque si bien este dispone de guías científicas cuando éstas le faltan, llena las lagunas con la intuición y no suspende la acción. Otro aspecto que considera es el de las finalidades. Para el práctico el criterio pragmático es la prueba de sus actos, si éstos producen los resultados deseados, los criterios quedan justificados. Para el científico, el criterio pragmático se subordina al de la importancia teórica.

La influencia de Greenwood en el Trabajo Social de América del Sur ha sido importante, ello fue a partir de su estadía en 
Chile o través de discípulos que fueron becados a Estados Unidos, lugar de su desempeño académico.

Nos valemos de esta breve exploración para señalar que las expresiones que bregaban por la importancia de la investigación en trabajo social lo hacen desde un sentido de "aplicabilidad" de los conocimientos producidos. Asimismo observamos que esta clasificación de la ciencia y de la investigación tiene su razón de ser en la matriz positivista cuyo carácter hegemónico ha impregnado las ciencias sociales en general.

De igual forma en este recorrido no se observan discernimientos acerca de los modos de construcción de conocimientos y sus supuestos epistemológicos, tampoco se advierten mayores cavilaciones frente a la homologación de la investigación social con el dominante método científico de las ciencias naturales.

Este panorama nos permite hacer algunas apreciaciones, en principio que la investigación en Trabajo Social estuvo más que nada restringida a los ámbitos académicos y, podemos sostener con bastante firmeza que, en nuestro contexto, nunca logró constituirse en una perspectiva que fuera asumida mayoritariamente por el colectivo disciplinar, sino que más bien tuvo una ubicación marginal.

Por otra parte, pautas trazadas de antemano han provocado que la producción de conocimientos, expresión de la práctica investigativa, fuera caracterizada como manifestación de posturas teoricistas, y por lo tanto desencontradas de la intervención y de los intereses reales y genuinos del Trabajo Social. Se ha visto a la investigación como una actividad reservada y específica de los teóricos, como una "práctica" que se desarrolla alejada de la inmediatez de los hechos cotidianos que constituyen el substrato de la intervención.

Frente a ello creemos que Trabajo Social no puede consolidar su autonomía relativa si no participa "como campo" de la producción de conocimiento de aquellos procesos y cuestiones en los que se halla implicada su práctica. Coincidimos con Norbert Elías cuando plantea que el término autonomía relativa presenta la ventaja de que sirve para impugnar la idea, tan arraigada entre algunos especialistas,

...de que es posible realizar investigaciones de forma totalmente autónoma e independiente de las que realizan los representantes 
de otros campos científicos. La autonomía relativa es en este sentido, el símbolo de la necesidad de una cooperación más cercana y más continuada entre los representantes de diferentes disciplinas académicas. Elías (1994).

En esa línea pensar desde la idea de autonomía relativa es una invitación a copensar junto a otros, a re-construir lo social que a diario fragmentamos. La tarea de investigación presenta buenas condiciones para transitar esta experiencia de pensar complejamente.

\section{Los desafíos actuales}

El escenario actual de esta región y más específicamente de nuestra institución da cuenta de reconfortantes transformaciones. Varias son las cuestiones que permiten consolidaciones en el campo disciplinar. Comienzan a instalarse los estudios de cuarto nivel, con distintas propuestas de postgrado (especializaciones, maestrías, doctorados). Paulatinamente la práctica investigativa se fortalece con la presentación de cada vez más proyectos de investigación. Cobran importancia los debates epistemológicos, y ello desencadena fructíferas discusiones que permiten repensar los modos de aprehensión de lo real que se ponen a jugar tanto en la construcción del objeto de estudio como en los procesos de intervención profesional.

En el análisis de las distintas perspectivas epistemológicas emerge una fuerte crítica al positivismo (teorías del orden) así como a su modo de clasificar a las ciencias. En ese marco se cuestiona el lugar asignado a Trabajo Social en el "hacer", lo que ha vedado y aún opera autovedando la autorización para producir conocimientos.

Sabemos que el "discurso" de Trabajo Social paulatinamente ha comenzado a circular a nivel de la comunidad científica, sabiendo que lo que está en juego es la autoridad científica, la capacidad de imponer criterios de verdad, de cientificidad. De allí que no es poca la energía que estamos poniendo ya que se trata de un espacio de lucha altamente competitivo y cuyas reglas de juego están ordenadas en base a criterios elaborados desde las posiciones dominantes. 
Estela Grassi a propósito de este tema enuncia que la relación que Trabajo Social ha tenido con la producción de conocimientos ha sido conflictiva. La autora se pregunta

...por qué, tratándose de un campo profesional cuyo objeto son las diversas manifestaciones del conflicto y la contradicción de relaciones sociales, expresadas (o conceptualizadas) como problemas sociales, hay, sin embargo, tan poco, (o nada) de aporte por parte de los trabajadores sociales, en el conocimiento de su propio objeto. Grassi (1995).

Una de las hipótesis que puede dar respuesta a esta situación se encuentra en que la necesidad de producir conocimientos no fue una perspectiva hegemónica en nuestro campo disciplinar. Actualmente y como consecuencia de intensos debates se visualiza la estrecha relación entre interpretación e intervención. La histórica dicotomía entre pensar y hacer muestra su inconsistencia al quedar de relieve que todo "hacer" tiene en sí un "modo de pensar, un modo de ver". Ello implica que nuestras prácticas están impregnadas de teorías (implícitas o explícitas), por ello constituye un imperativo profesional reconocer y tensionar estas herramientas teóricas con los procesos sociales en los cuales Trabajo Social interviene para de esta manera ir construyendo las mediaciones teóricas que permitan comprender y dar cuenta de la dinámica social.

En nuestra unidad académica desde hace unos quince años se viene produciendo un intenso proceso de desarrollo de proyectos de investigación. La profundización y continuidad en determinadas temáticas posibilitó la construcción de líneas de producción-algunas compartidas con extensión y tesis de maestrías. Entre ellas: Pobreza y condiciones de vida;

Políticas Sociales y gestión; Mujer y teorías de género; Estudios sobre Familia; Campo disciplinar de Trabajo Social; Estudios sobre Universidad - Educación; Teoría Social; Dimensión cultural.

La conformación de los equipos de investigación es contenedora de distintas formaciones disciplinares. Si bien esta condición no implica necesariamente que el tratamiento del objeto de investigación sea interdisciplinario o transdisciplinario, podemos advertir que hay esfuerzos e intención de trascender la mirada unilateral. 
Todo este proceso ha reportado en acumulaciones que nos permiten ambicionar un lugar de mayor participación en la construcción de "discursos acerca de lo social". Sabemos que los discursos inscriben prácticas. En esa línea la profesión puede hacer aportes a interpretaciones que contribuyan a pensar una sociedad más incluyente e igualitaria.

Esta tarea debe ser asumida por el colectivo profesional en su conjunto en la idea de resignificar al propio Trabajo Social y desplazarlo de su ubicación tradicional en el solo hacer. La apuesta por una mayor consolidación del campo disciplinar nos pertenece a todos los profesionales.

Paraná, agosto de 2008.

\section{Bibliografía}

BARTLETT, H. (1968). "El lugar y la aplicación del saber". Selecciones del Social Work $\mathrm{n}^{\circ} 1$ (p. 12).

CASTILLO, J. J. (2003). En la jungla de lo social. Reflexiones y oficio de sociólogo. Buenos Aires: Miño y Dávila.

ELÍAS, N. (1994). Conocimiento y poder. Madrid: Ediciones de la Piqueta.

FANFANI, E. T. (1989). Estado y pobreza: estrategias típicas de intervención/1. Buenos Aires: Centro Editor de América Latina.

GRASSI, E. (1995). "La implicancia de la investigación social en la práctica del Trabajo Social". Revista de Trabajo Social. Año 4, no 9 (p. 59).

GREENWOOD, E. (1959). "Una teoría de las Relaciones entre la Ciencia Social y el Trabajo Social". Revista Mexicana de Sociología. Año XXI, Vol. XXI, nº 2 (p. 543).

MACDONAL, M. E (1966). "Investigación de la acción social: una perspectiva", en Polansky, N.: Metodología de la investigación en Trabajo Social (p. 28). Madrid: Colección A/S.

PERROT, M. (2000). "Salir", en Duby, G. y Perrot, M.: Historia de las mujeres. El siglo XIX (p. 486). Madrid: Taurus.

RAMOS GOROSTIZA, J. L. (2003). "Beatrice Webb y su influencia como economista". Contribuciones a la Economía, (en www.eumed.net/ce/jlrg-webb.htm).

VIGETTI, A. T. (1965). La investigación en Servicio Social. Buenos Aires: Humanitas. 